\title{
Learner Perceptions of Instruction in L2 Pragmatics
}

\author{
Yuanshan Chen \\ Department of Applied English, National Chin-Yi University of Technology \\ 411 Taichung, Taiwan \\ Tel: 886-4-2360-0752Ｅ-mail: yuanshan@ncut.edu.tw
}

\begin{abstract}
In Taiwan, pragmatic competence has often been a neglected area in English education. Learners may be linguistically competent, but do not know how to use L2 appropriately. Through the teaching of complaint behaviors, the author demonstrates how pragmatic components can be incorporated into a college-level language classroom. After the instruction, the self reports of the forty participants showed a positive attitude toward such instruction. They also reported that the teaching materials were suitable, but suggested that the instruction would have been more interesting if videos or films had been included. When it comes to learning difficulties, most learners reported that more instructional time was needed to turn knowledge about L2 complaints to actual productions. These findings can serve as offering advice to language teachers when they plan their lessons in L2 pragmatics.
\end{abstract}

Keywords: L2 pragmatics, Instruction, Complaint

\section{Introduction}

Teachers in Taiwan generally pay a great deal of attention to grammar to help learners internalize linguistic rules. Learners therefore have fewer opportunities to encode their intent in the language they are learning. This can cause trouble when Taiwanese students go abroad to pursue advanced study in an English speaking country. The following example is a real-life story happening to one of my students - John, who was admitted to an American university with 580 TOEFL scores at that time. One day, John was invited to his advisor's house for dinner. The professor and his wife welcomed him, and they had a wonderful meal during which John talked at lot about Taiwan. Before he knew it, John realized it was 11:00, and he thought it was time for him to leave. Therefore, he said to the professor, "It's very late. Thank you for the dinner. I think I should go now because you might need to go to bed." Though grammatically perfect, John's utterance upset the elderly couple. The professor's wife even responded in unfriendly terms: "You may go home if you want to. Don't say it is because we want to go to bed!"

What had John done wrong? His mistake arose not from violations of grammatical rules, but from inadequate pragmatic knowledge in the target language. As Bardovi-Harlig et al. (1991) put it:

Language learners interacting with speakers of a target language must be exposed to language samples which observe social, cultural, and discourse conventions - or in other words, which are pragmatically appropriate. Speakers who do not use pragmatically appropriate language run the risk of appearing uncooperative at the least, or, more seriously, rude or insulting. This is particularly true of advanced learners whose high linguistic proficiency leads other speakers to expect concomitantly high pragmatic competence. (p.4)

This assertion has two implications that, first, learners' pragmatic proficiency may not go hand in hand with their linguistic proficiency. Rather, learners at various proficiency levels may use inappropriate language in a given situation. What differentiates advanced learners and beginners is that the former are expected to have a better understanding of situational appropriateness in their L2 discourse. Second, an environment with rich, authentic language samples is important in that it helps learners in the acquisition of pragmatic conventions in the target language. Unfortunately, in a monolingual environment like Taiwan, it is not easy for learners to surround themselves with large amounts of L2 input, thus inhibiting pragmatic proficiency. In addition, teachers, even in a communicatively oriented classroom, do not pay particular attention to developing learners' sociolinguistic competence (Yu, 2008). Therefore, the purpose of this study is to show how pragmatic components can be incorporated in the language classroom and what learners perceive about such instruction.

\section{Theoretical Background}

\subsection{Rationale for Teaching L2 Pragmatics}

In SLA research, there has been a consensus that the learner, no matter in a tutored or an untutored learning environment, must pass through a certain stage regardless of their age and L1 background (Larsen-Freeman \& Long, 1991). Since the routes of learning for all the language learners are identical, researchers such as Krashen (1982) argue that learners can benefit most if they are allowed to construct their interlanguage system along a natural route. However, a large body of morphosyntactic studies has demonstrated that although formal instruction cannot change the order of 
acquisition, it has two advantages. First, formal instruction has a beneficial effect on the process of language development, rate of acquisition and ultimate level of attainment. Second, through practice, routinization and consciousness-raising in the classroom, formal instruction can transform from learning to acquisition, from explicit to implicit knowledge, and from controlled processing to automatic processing (Bialystock, 1982; Pavesi, 1984; Sharewood Smith, 1981, Tarone, 1983).

Compared to the morphosyntactic studies, relatively fewer experiments compare L2 pragmatics acquired in natural and classroom settings. The most significant experiment was conducted by Bouton (1999). He found that although implicature can be acquired in a natural setting, the process took as long as 33-months to 4-7 years. However, through instruction, the process can be shortened. In his study, Bouton categorized two types of implicature. Idiosyncratic implicature is unconventional and requires listener's ability to draw inferences, while formulaic implicature can be interpreted by convention. Idiosyncratic implicature was found to be easier for the newcomers prior to the instruction. However, after six hours of formal instruction, the learners' interpretations of formulaic implicature reached the same level as those who have resided in the United States for seventeen months to seven years. Bouton's findings lend support to the fact that teaching L2 pragmatics may not alter the route of acquisition, but can accelerate the process of acquisition.

\subsection{Approaches to Teaching L2 Pragmatics}

The research on instructional approaches in L2 pragmatics has started to take shape since the early 1990s, but the relevant reports are not very many in comparison with those on how instruction influences other aspects of second language acquisition. In these studies, researchers often ask the question: "If instruction improves learners' pragmatic competence, which teaching approach is the most effective?" To answer this question, they generally compare two kinds of approaches in teaching L2 pragmatics: explicit and implicit. The major difference is that explicit teaching provides learners with detailed metapragmatic information, while implicit teaching does not. Despite a few exceptions, most of the intervention studies to date have demonstrated that the learners who receive explicit instruction outperform those who receive implicit instruction (Rose, 2005).

Explicit instruction of pragmatic rules in general follow the traditional "Three P's methodology" (Presentation-Practice-Production) (McCarthy, 1998). At the presentation stage, the native speaker model (the NS model) is important because it offers examples of language in use. The model can be short extracts derived from authentic materials such as films, telephone conversations, and television programs. It can simply be interactions between two native speakers of the target language (usually the instructor and another native speaker) or explanatory handouts which identify metapragmatic details necessary for the acquisition of the target form (e.g. Rose \& $\mathrm{Ng}, 2001$, Takahashi, 2005).

At the practice stage, learners are given tasks which can reinforce the pragmatic knowledge they have acquired. At this stage, both sociopragmatic and pragmalinguistic information of the given tasks are encouraged to be clarified by the learners. In this way, learners have the opportunities to ask the instructor about the cultural information, vocabulary and structures associated to complete the tasks (Yoshimi, 2001).

Finally, at the production stage, teachers may use discourse completion test (DCT) or role plays to elicit learners' performance. In the DCT, learners have time to plan what they intend to express on a written format, but there is no interlocutor involved. On the other hand, in role plays, learners can acquire interactional skills such as conversational management, manipulation of turn-taking mechanism, use of intensifiers and downgraders, and accurate choice from a range of strategies (House, 1996). Olshtain \& Cohen (1990) suggest that corrective feedback and discussion are useful teaching techniques after learners present their talks. The instructor, together with the whole class, can comment on the appropriateness of the performances in terms of coherence of organization, strategy use, as well as lexical and grammatical productions, or the learners can be invited to contrast their perceptions, expectations, and awareness of L1 and L2 cultures.

In addition to the three P's methodology, raising learners' awareness as a warm-up activity is important, too. Bou-Franch \& Garces-Conejos (2003) claim that awareness raising tasks can promote learners' sociopragmatic knowledge about the target feature under investigation. One feature that is frequently observed in the awareness-raising phase is the discussion of the target feature represented in both L1 and L2, which makes pragmatic concepts easier to access (Rose \& Ng, 2001). For example, in Liddicoat and Crozet's (2001) study, where the French utterance "Did you have a good weekend" was taught to a group of Australian students, learners were first asked to talk about the stereotypes they held for both Australian and French people. Then the teacher and learners worked out possible Australian and French equivalences to the question under study. Finally, the teacher explained how this question functions differently in Australian and French contexts. Through constant practices, learners are believed to gradually possess the ability to observe and analyze sociological variables in real encounters. Eslamin-Rasekj (2005) pointed out that teacher presentation and discussion as well as student discovery are the two useful teaching techniques to raise learners' awareness. In teacher presentation and discussion, the teacher can inductively or deductively relay information 
derived from pragmatic research findings. For example, the teacher may introduce how participants, their status, the situation are connected together. In the activity of student discovery, learners become ethnographers and are asked to observe or record naturally occurring data. This activity will help learners become keen to how a particular feature is used in L1 and L2.

\section{The study}

\subsection{The Setting}

The participants of the study were 40 English majors who enrolled in the "Speech and Communication" course provided by the Department of Applied Foreign Languages of Ling Tung University in Taiwan. One section of this course was planned for this study, which aimed to teach the learners how to make complaints appropriately in English. This speech act was chosen because it receives comparatively less attention than other acts such as apologies, requests and compliments in the textbooks on the market. The other reason for choosing this speech act is that without knowledge about L2 complaints, learners may avoid expressing dissatisfaction and remain frustrated when facing an offense, or they may make an inappropriate complaint which endangers the speaker-hearer relationship.

\subsection{The Teaching Materials}

The primary teaching material used in this study was entitled Say It Naturally: Verbal Strategies for Authentic Communication (Level 2) (Wall, 1988). Chapter 4 of this book specifically addresses how to make complaints. The chapter starts with an introduction of American complaints and discusses the social contexts in which complaints are most likely to be employed. In the section of Verbal Strategies, the author arranged the complaint strategies from formal to informal with regard to setting, audience, speakers and gender. Learners may also listen to Situational Dialogues, which provide native speaker models demonstrating how these verbal strategies are used in natural, true-to-life situations. There are three questions following each conversation, with which learners may discuss the language as well as the cultural aspects of dialogues. Practices, Dialog Completions, and Role Plays are exercises to help reinforce newly learned strategies. They are arranged from easy to difficult, and from controlled to open-ended.

In addition to the textbook, supplementary handouts were designed to compensate for the lack of metapragmatic information in the book. There were two major topics on the handouts. The first topic introduces the notions of power, distance and degree of imposition as well as the effect of these social parameters on strategy choice. The second topic addresses a series of decision making procedures after evaluating social context and the corresponding strategies are also introduced. It deals with linguistic realizations of each strategy and concerns how strategies can be combined together to make complaints more complete.

\subsection{The Teaching Procedures}

Building on the 3P's methodology, I designed seven teaching steps and used them in my class. The entire lesson lasted 10 hours.

\section{Step 1: Awareness-raising session}

In the first class, I asked the learners to organize into groups and discussed the two questions on the board.

1. Under what circumstances is it necessary for you to make complaints? According to your understanding of the American culture (e.g. contacts with Americans or seeing American movies), do you think Americans make complaints in similar situations as Chinese do? Please answer the question based on your experiences or observations and illustrate with example(s).

2. When making complaints in Chinese, do personal factors such as age, gender, social status, and degree of intimacy of the hearer make any difference to you in the choice of language? If so, which factor(s) do you think would affect your speech the most? Please illustrate with example(s). Are the same factors determining your making complaints in English? Please illustrate with example(s).

The purposes of this brainstorming session were to ask the learners' stereotypical impression of how Americans and Chinese make complaints and to activate their interests in learning American complaint behaviors. The learners were given fifteen minutes to discuss the two questions. After the discussion, each group selected a representative to report their conclusions. The entire discussion session was conducted in Chinese and lasted about thirty minutes.

\section{Step 2: Social contexts session}

Bou-Franch \& Carces-Conejos (2003) contend that sociopragmatics should be introduced before pragmalinguistics because "developing L2 sociopragmatic knowledge will result in the improvement of the production and interpretation of L2 pragmalinguisitc strategies" (p.2). Therefore, in this step, I drew on Brown \& Levinson's Politeness Model and presented to the learners how power, distance and severity of offense are intertwined to affect choice of language. I also showed to the learners such interplay may be different in the western and Chinese cultures. 


\section{Step 3: Strategy session}

At this stage, I told the learners that they were faced with three basic options after evaluating the social contexts: Do not make complaints, Make complaints less directly and Make complaints directly. I also analyzed the payoffs of the three options for the learners. After the analysis, I presented to the learners the complaint strategies for each option. The corresponding strategy of Do not Make Complaints is Opting out. Make complaints less directly includes Dissatisfaction and Request for repair with I as subject. Finally, Make complaints directly includes Interrogation, Accusation and Threat, with You as subject. For each individual strategy, I provided the learners with functional, situational and linguistic information. Functional information refers to what intention the speaker may convey by using this particular strategy. Situational information refers to the social context in which a given strategy can be used appropriately. Finally, linguistic information refers to the pragmalinguistic aspect of a strategy, which may include tense, sentence patterns, or reference to speaker or hearer. Table 1 shows the strategies.

\section{Insert Table 1 here.}

Step 4: Practice session

At this stage, I asked the learners to do Practice 1 and 2 on pages 56-58 in the textbook. Each practice is composed of five scenarios. I demonstrated how to do the practice. After I demonstrated how to do the practice, the learners were asked to read the scenario, evaluate the social contexts in which the scenarios occur, and then write down the responses to the scenarios within one turn. The writing tasks have two advantages. First, though in the written form, the DCT elicits representations of spoken language (Rintell \& Mitchell, 1989) and the learners had more time to plan what they would say. According to Cohen (1996), learners who do planning before production are prone to follow sociocultural and sociolinguistic conventions than those who do not. Second, the learners could have the opportunity to focus on form in addition to meanings. Krashen's Monitor Model (1982) states that there are three conditions for a performer to be conscious of linguistic forms - the performer has to have enough time, the performer has to be thinking about correctness and the performer has to know the rule. After the learners knew how to respond to an offense within one turn, I asked them to do Dialogue Completion in the textbook on pages 63-65. Again, the learners were asked to evaluate the social contexts before writing down the responses. During their writing, I circled around the classroom to see if the learners had any questions about strategy use. Practice and Dialogue Completion provide more controlled activities and help the learners to extend making complaints from a single to multiple conversational turns, which pave the way for more open activities like role plays.

\section{Step 5: Role play session}

After the learners understood how the complaint strategies could be appropriately used, they were asked to perform the role play tasks on pages 66-67 in the textbook. Unlike Practice and Situational Dialogue, these role plays are open ended. I asked the learners to work in pairs, to take on the imaginary roles and respond to the scenarios orally. At this stage, the learners were asked to do impromptu planning without writing down the responses.

\section{Step 6: Feedback session}

In this session, I nominated several pairs to come to the front to perform the role plays. The whole class watched the role play performances. After each role play, the class gave feedback, which included the appropriateness of language use, norms of interactions, or even body language. The feedback session was important since research shows that learners generally benefit from the comments they receive (Olshtain \& Cohen, 1991).

\section{Step 7: Wrap up}

In order to reinforce what was taught in class, I asked them to think of five situations in which they could make complaints in American English as homework assignments. In addition, the learners had to write down why they responded in this way. These situations could be imaginary or real-life situations. I selected some of the assignments and discussed them in class.

Table 2 shows the instructional steps, accompanied by the materials used and time allocation.

\section{Insert Table 2 here.}

\section{Results and Discussion}

After the instruction, the forty learners were asked to write self reports concerning their perceptions of explicit instruction. The three questions are:

1. Do you think you benefited from instruction in making complaints in English? Why or why not? Please state your reasons.

2. Do you think the teaching materials are suitable? Why or why not? Please state your reasons.

3. During instruction, what difficulties did you encounter? Please state your reasons. 


\subsection{General Impressions}

In the learners' self reports, thirty-four out of the forty learners $(85 \%)$ reported that the instruction was a special and new experience for them because complaint behaviors had never been fully discussed in previous English courses. For example, Rita said,

(1) I think the teaching of complaint strategies was special. We have never had any course which said particular attention to this. We might have a little understanding of how to make complaints from the English conversation courses we have taken before, but there was surely no specific teaching of these strategies.

Lisa also commented,

(2) I think the instruction was a fresh experience to me. In other conversation classes, the teachers did not explain any strategies or rules. They just wanted us to follow the textbook models and do the role plays. So I feel that the teaching is different from the one we had before.

Twenty-one out of the forty learners (53\%) also mentioned that the treatments were helpful to them in that they started to think of interlocutor relationships before they issued the complaints. For example, Dan remarked,

(3) I think the course content was really useful because I've learned how to make complaints more appropriately. I have the idea of social power and social distance when I make complaints in Chinese. I know that I should use more polite language when I speak to the chairperson, and I may use less polite language when I speak to my brother. But I have difficulty complaining in English, not to mention thinking about if the other person is higher in status or we have a close relationship. From the instruction, at least I know that I should develop the habit of considering the context in the first place before uttering the complaints in English.

Nineteen out of the forty learners (48\%) reported that the linguistic strategies provided allowed them to vary their complaints under different circumstances. For example, Paul said,

(4) It has been difficult for me to complain in English. This may be because English is not my native language. Usually I don't know how to express my complaints to an American. The complaints I made were usually Chinese like, and I tended to use the same expression over and over again in different situations. This is because I didn't know that there are other ways to make complaints. This class has taught me strategies which I can use based on the situations I encounter. Although they are somewhat formulaic and take me a while to remember them, I think they can improve my English ability in this respect.

The learners' feedback supports the call for incorporating the teaching of L2 pragmatics into language curriculum. For the past decades, many interlanguage pragmatics studies have indicated that even advanced L2 learners deviated from the target language norms. They may produce grammatically correct but pragmatically inappropriate utterances. One of the reasons to explain the deviations is that learners do not always transfer from what has been available to them, for example, from pragmatic universals or L1-based knowledge (Kasper, 1997). The other reason is that certain language-specific features need to be drawn to attention because simple exposure to sociolinguistically appropriate L2 input is not sufficient for learners to acquire L2 pragmatic knowledge (Schmidt, 1993).

The learners' positive attitudes towards the explicit instruction can also be observed in other studies. For example, Olshtain \& Cohen (1990) reported that most students in their study highly valued the teacher's explanations of English apology realizations and the information sheets pertaining to the main points of the lesson. They attributed the learners' preference for formal presentation to the fact that adult learners may have felt more comfortable with explicit presentation of realization patterns than with experiential types of activities. Tateyama (2001) also noted in her study that almost all the students in the explicit group favored the teacher's explicit explanation about the use of routine expressions. They also mentioned that input-only instruction would not have been sufficient for them to understand a variety of expressions.

\subsection{Teaching Materials}

Thirty-five learners $(88 \%)$ felt that the main textbook and the supplementary materials provided them with sufficient information about how to make complaints in American English. For example, Judy said,

(5) I think the instructional materials are rich in content. The textbook contains many complaint situations, and the supplementary materials provide us with many rules and useful expressions. Before the instruction, I could only use a few sentences to express myself. I think the handouts we used are clear and understandable. They meet our current level of proficiency and clearly convey what the teacher was trying to teach us. Compared with the textbook, the handouts explain the rules very clearly and the examples relate to daily conversations. I can learn how to make complaints through the handouts.

Peter also commented,

(6) I think the handouts were very useful to me. Through the handouts, I could clearly understand what the teacher 
was trying to convey. I felt that I was learning something. The textbook was ok. There were not so many rules, but it had many role play activities.

The learners' evaluations of teaching materials reflected the complementary functions of textbook and supplementary materials. Basically, the textbook provides learners with an array of scenarios for communicative practices, which range from the most controlled DCT type of activities to the least controlled role play activities. On the other hand, the teacher's materials provide the learners with detailed metapragmatic information to supplement the textbook which does not seem to give a complete picture of L2 complaints.

Although most learners highly valued the teaching materials used in the instructional sessions, twelve out of the forty learners (30\%) suggested that the use of videos or movies may have made the instruction more interesting. For example, Edward remarked,

(7) Maybe the teacher can let us watch movies to help us better understand how Americans make complaints. I think it would be more interesting than just stating the rules or practicing conversations.

It is true that the use of authentic audio-visual materials such as television dramas, movies, or commercials in language classrooms give the learners a much better understanding of cultural and linguistic norms of the target language. These multi-media audio-visual materials have the following advantages. First, they make classroom teaching more interesting. Second, they provide a great number of conversations with a variety of expressions spoken in the target language. Third, they help enhance not only learners' pragmatic competence, but also strategic competence because through authentic materials, learners may learn how to control topic, take turns and repair communication breakdowns. Finally, they supply not only verbal behaviors but also nonverbal communication strategies such as gestures and eye contact between interlocutors (Soler, 2005).

However, the use of authentic movies or television programs may be a good teaching approach, but it also poses problems for language teachers who attempt to teach the speech act of complaining. Compared with speech acts such as apologies, requests, excuses and closings, it is more difficult to capture what counts as complaints since they have no stereotypical forms and no corresponding second part. Edmonson (1981) claims that the perlocutionary intent of a complaint is negotiable because a hearer cannot identify by convention what behavior will satisfy the act of complaining. Moreover, complaint as the first part of an adjacency pair can be followed by denial, rejection, justification or making excuses (Laforest, 2002). Such complexities increase the degree of difficulties of finding suitable film segments for instruction. Therefore, the better option for language teachers may be to use audio-visual materials with tailor-made complaint scenarios. As long as efforts are made to preserve naturalness, these audio-visual materials can meet the learners' needs and achieve teaching outcomes more successfully than natural film segments, soap operas or movies.

\subsection{Learning Difficulties}

When asked about if there were any difficulties in learning how to complain in English, thirty out of the forty learners $(75 \%)$ reported that they needed to learn a lot during a short period of time and that they were not used to the newly learned strategies. For example, Richard commented,

(8) I think the problem for me is that there are too many complaint strategies. It is easy for me to get confused with those strategies. I cannot digest all the information I learned in class. I need to take some time to distinguish these strategies and remember how to use them appropriately. Though I've learned the rules, it is not easy for me to speak the language as well as native speakers do.

Lily also remarked,

(9) The strategies are useful, but it seems that I couldn't take in too much at a time. Sometimes I would forget what the teacher taught us in the last hour. Before the instruction, I didn't have to think about these strategies. The sentences may have popped into my mind, although I knew they might not be right. Now I have to think about which strategy to apply in which situation. I know it's good for me, but I need some time to get used to it.

The learners' reports showed that they needed more time to digest what they had learned. Faerch \& Kasper (1984) distinguished between declarative pragmatic knowledge and procedural pragmatic knowledge. The former is "knowledge that" and deals with "an individual's knowledge of the rules and elements of one or more language(s), not related to specific communicative goals or to language use in real time", while the latter is "knowledge how" and "selects and combines parts of declarative knowledge for the purpose of reaching specific communicative goals, observing constraints imposed by language processing in real time" (p.215). The components of declarative pragmatic knowledge include linguistic knowledge, speech act knowledge, discourse knowledge, sociocultural knowledge, context knowledge and knowledge of the world. On the other hand, the components of pragmatic procedural knowledge include goal-formation and context-analysis, verbal planning and monitoring execution. The speaker must establish a communicative goal based on context-determining factors, plan and select linguistic knowledge to meet the communicative goal, and monitor the feedback provided by the other interlocutor in the interaction. 
Educational psychologists such as Anderson (1985) have claimed that learning is a process where declarative knowledge gradually becomes procedural knowledge. It holds true for interlanguage pragmatics as well. Drawing on Anderson's work, Ellis (1990) classified learning into three stages: the cognitive stage, where learners are conscious of the rules; the associative stage, where they begin to proceduralize the knowledge they acquire; and the autonomous stage, where they perform the language automatically and errors disappear. The learners' self-reports showed that the instruction may have been enough to give the learners declarative knowledge about L2 complaints, but it may have been insufficient for the learners to transform all the rules they had acquired to actual productions.

In fact, treatment lengths vary among previous intervention studies, ranging from two or three 20-min sessions to nine week instructional period (Rose, 2005). Kasper (2001) argues that very short period of treatment can be effective if there are learning opportunities inside and outside the classroom. However, her suggestion may not be applicable to the foreign language environment because there is no such input outside the classroom. Therefore, EFL teachers should allocate more instructional time than ESL teachers in improving learners' pragmatic competence. The more complicated the targets (e.g. complaining) are, the more instructional time is required.

\section{Conclusion}

In this paper, I demonstrated seven steps in teaching L2 complaints and reported learner perceptions of the instruction in light of general impression, teaching materials and learning difficulties. The findings revealed that instruction in L2 pragmatics is feasible and beneficial because most of the learners held a positive attitude towards the instruction. The English teachers in Taiwan are therefore encouraged to include L2 pragmatics into their curriculum. They are also encouraged to consider the use of audio-visual information and the problem of instructional length when they do lesson planning, as suggested by the learners in the self reports.

\section{References}

Anderson, J. (1985). Cognitive psychology and its implications ( $2^{\text {nd }}$ edition). New York: Freeman.

Bardovi-Harlig, K., Hartford B. S., Mahan-Taylor, R., Morgan, M. J. \& Reynolds, D. W. (1991). Developing pragmatic awareness: Closing the conversation. ELT journal, 45, 4-15.

Bialystock, E. (1982). On the relationship between knowing and using linguistic forms. Applied linguistics, 3, $181-206$.

Bou-Franch, P. \& Garces-Conjos, P. (2003). Teaching linguistic politeness: A methodological proposal. IRAL 41, 1-22.

Bouton, L. (1999). Developing nonnative speaker skills in interpreting conversational implicatures in English: Explicit teaching can ease the process. In E. Hinkel (Ed.), Culture in second language teaching and learning (pp. 47-70). Cambridge University Press.

Cohen, A. D. (1996). Developing the ability to perform speech acts. SSLA 18, 253-67.

Edmonson, W. J. (1981). On saying you're sorry. In F. Coulmas (Ed.) Conversational routine (pp. 273-86). The Hague: Mouton Publishers.

Ellis, R. (1990). Instructed second language acquisition. Oxford University Press.

Eslami-Rasekh, Z. (2005). Raising the pragmatic awareness of language learners. ELT Journal 59, 199-208.

Faerch, C. \& G. Kasper. (1984). Pragmatic knowledge: Rules and procedures. Applied linguistics 5, 214-25.

House, J. (1996). Developing pragmatic fluency in English as a foreign language: Routines and metapragmatic awareness. SSLA 18, 225-52.

Kasper, G. (2001). Classroom research on interlanguage pragmatics. In K. R. Rose \& G. Kasper (Eds.), Pragmatics in language teaching (pp. 33-60). Cambridge University Press.

Kasper, G. (1997). Can pragmatic competence be taught? Honolulu: University of Hawaii, Second Language Teaching \& Curriculum Center

Krashen, S. (1982). Principles and practice in second language acquisition. Pergamon.

Laforest, M. (2002). Scenes of family life: Complaining in everyday conversation. Journal of pragmatics, 34, 1595-1620.

Larsen-Freeman, D. \&. Long, M. H. (1991). An introduction to second language acquisition. New York: Longman.

Liddicoat, A. J. \& Crozet, C. (2001). French interactional norms through instruction. In K. R. Rose \& G. Kasper (Eds.), Pragmatics in language teaching (pp. 125-44). Cambridge University Press.

McCarthy, M. (1998). Spoken language and applied linguistics. Cambridge University Press.

Olshtain E. \& Cohen, A. D. (1990). The learning of complex speech act behavior. TESL Canada journal, 7,45-65.

Pavesi, M. (1984). The acquisition of relative clauses in a formal and in an informal setting: Further evidence in support of the markedness hypothesis. In D. Singleton \& D. Little (Eds.), Language learning in formal and informal contexts 
(pp. 151-63). IRAAL, Dublin.

Rintell, E. M. \&. Mitchell, C. J. (1989). Studying requests and apologies: An inquiry into method. In S. Blum-Kulka, J. House \& G. Kasper (Eds.), Cross-cultural pragmatics: Requests and apologies (pp. 248-72). New Jersey: Ablex Publishing Co.

Rose, K. R. (2005). On the effects of instruction in second language pragmatics. System, 33, 385-99.

Rose, K. R. \& Ng, C. (2001). Inductive and deductive teaching of compliments and compliment responses. In K. R. Rose \& G. Kasper (Eds.), Pragmatics in language teaching (pp. 145-70). Cambridge University Press.

Schmidt, R. (1993). Consciousness, learning and interlanguage pragmatics. In G. Kasper \& S. Blum-Kulka (Eds.), Interlanguage pragmatics (pp. 21-42). Oxford University Press.

Sharwood Smith, M. (1981). Consciousness-raising and the second language learner. Applied linguistics, 11, 159-68.

Soler, E. A. (2005). Does instruction work for learning pragmatics in the EFL context? System, 33, 417-35.

Takahashi, S. (2005). Noticing in task performance and learning outcome: A qualitative analysis of instructional effects in interlanguage pragmatics. System, 33, 437-61.

Tarone, E. (1983). On the variability of interlanguage systems. Applied linguistics,4, 142-63.

Tateyama, Y. (2001). Explicit and implicit teaching of pragmatic routines. In K. R. Rose \& G. Kasper (Eds.), Pragmatics in language teaching (pp. 200-222). Cambridge University Press.

Wall, A. P. (1988). Say it naturally: Verbal strategies for authentic communication (Level 2). New York: Harcourt Brace \& Company.

Yoshimi, D. R. (2001). Explicit instruction and JFL learner's use of interactional discourse markers. In K. R. Rose \& G. Kasper (Eds.), Pragmatics in language teaching (pp. 223-44). Cambridge University Press.

Yu, M. C. (2008). Teaching and learning sociolinguistic skills in university EFL classes in Taiwan. TESOL Quarterly 42, $31-53$.

Table 1. Complaint strategies

\begin{tabular}{|c|c|c|c|}
\hline Options & Formulas & Functions & Examples \\
\hline $\begin{array}{l}\text { Do not make } \\
\text { complaints }\end{array}$ & Opting out & $\begin{array}{l}\text { The speaker ignores the offense } \\
\text { to avoid conflict. }\end{array}$ & N/A \\
\hline \multirow[t]{2}{*}{$\begin{array}{l}\text { Make complaints } \\
\text { less directly }\end{array}$} & Dissatisfaction & $\begin{array}{l}\text { The speaker describes the } \\
\text { offense, but avoids explicit } \\
\text { mention of the hearer. }\end{array}$ & My letter was opened. \\
\hline & Request for repair & $\begin{array}{l}\text { The speaker asks the hearer to } \\
\text { make up for the offense or to } \\
\text { stop the offense. }\end{array}$ & Could I have some privacy? \\
\hline \multirow[t]{3}{*}{$\begin{array}{l}\text { Make complaints } \\
\text { directly }\end{array}$} & Interrogation & $\begin{array}{l}\text { The speaker questions the hearer } \\
\text { about the offense. }\end{array}$ & Why did you open my letter? \\
\hline & Accusation & $\begin{array}{l}\text { The speaker accuses the hearer } \\
\text { of the offense. }\end{array}$ & You opened my letter. \\
\hline & Threat & $\begin{array}{l}\text { The speaker asserts immediate } \\
\text { or potential sanctions against the } \\
\text { hearer. }\end{array}$ & $\begin{array}{l}\text { If you open my letter again, } \\
\text { I'll move out. }\end{array}$ \\
\hline
\end{tabular}

Table 2. Instructional steps, materials used and time allocation

\begin{tabular}{llll}
\hline Steps & Activities & Materials & Hours \\
\hline 1 & Awareness raising & Brainstorming questions & 0.5 \\
2 & Introducing social contexts & Handout 1 & 2 \\
3 & Introducing complaint strategies & Handout 2 & 2 \\
4 & Practicing complaint strategies & Textbook & 2 \\
5 & Performing role plays & Textbook & 2 \\
6 & Giving feedback & Teacher/peer evaluation & 0.5 \\
7 & Wrapping up & Learners' assignments & 1 \\
\hline Total & & & 10 \\
\hline
\end{tabular}

